\title{
DIFERENCIAS EN EL NIVEL DE COMPETENCIA MEDIÁTICA POR TIPO DE SISTEMA EDUCATIVO
}

\author{
CATALINA GonzÁLEZ-CABRERA' \\ Universidad del Azuay, Ecuador / cgonzalez@uazuay.edu.ec \\ Cecilia Ugalde SÁNCheZ² \\ Universidad del Azuay, Ecuador / cugalde@uazuay.edu.ec \\ LORENA PIEDRA ${ }^{3}$ \\ Universidad del Azuay, Ecuador / lore.piedram@gmail.com \\ JAIME LOJA4 \\ Universidad del Azuay, Ecuador / jaime.loja@tecazuay.edu.ec
}

Recibido: 31/3/2019 / Aceptado: 19/6/2019

doi: $10.26439 /$ contratexto2019.n032.4612

Resumen. La educación en alfabetización mediática en el Ecuador ha cobrado especial relevancia en la última década. Académicos e investigadores han señalado que en el país se necesita, además de reducir la brecha digital, capacitar a estudiantes, docentes y miembros de la sociedad en general en el uso y consumo de medios tanto tradicionales como digitales. En estudios anteriores se ha podido encontrar que el nivel de competencia mediática difiere por tipo de sistema educativo: privado, fiscomisional y público. La investigación desarrollada identifica si la tipología del sistema educativo (educación regular zona urbana, educación regular zona rural y educación flexible y a distancia) es un factor influyente en la generación de competencias. A través de un cuestionario y con el correspondiente análisis estadístico, se obtuvo que los estudiantes que asistían al sistema regular dentro de la urbe demostraron un nivel superior en competencias mediáticas frente a los demás participantes del estudio. Se encontraron diferencias entre el género, la edad y el nivel de competencias mediáticas. Las aplicaciones de estos

\footnotetext{
1 Doctoranda en Formación en la Sociedad del Conocimiento por la Universidad de Salamanca, España. https://orcid.org/0000-0002-1367-9337

2 Doctora en Marketing por la Universitat de València, España. https://orcid.org/0000-0001-7716-6023

3 Máster en Comunicación y Marketing por la Universidad del Azuay, Ecuador. https://orcid.org/0000-00029401-3958

4 Doctorando en Humanidades y Artes por la Universidad Nacional de Rosario, Argentina. https://orcid. org/0000-0002-7549-8646
} 
resultados son importantes para mejorar las políticas públicas tanto en educación y capacitación como en el acceso a la red y a las nuevas tecnologías.

Palabras clave: alfabetización mediática / competencia mediática / sistema educativo / Ecuador

\section{DIFFERENCES IN THE LEVEL OF MEDIA COMPETENCY BY TYPE OF EDUCATION SYSTEM}

Abstract. Education in media literacy in Ecuador has gained special relevance in the last decade. Both academics and researchers have pointed out that the country also needs to reduce the digital divide; and train students, teachers and all members of society in the use and consumption of traditional and digital media. Previous studies show that the level of media competency differs by type of education system, whether it is private, co-financed or public. This research determines if the type of education system (regular urban education, regular rural education, and flexible and distance education) is an influential factor in the generation of competencies. Through a questionnaire and the corresponding statistical analysis, it was concluded that students who attended the regular education system within the city demonstrated a higher level of media competency compared to the other participants of the study. Differences were found in gender, age and level of media competency. Applying these results is important to improve public policies in education, training and access to the Internet and new technologies.

Keywords: Media literacy / media competency / education system / Ecuador 


\section{DIFERENÇAS NO NIIVEL DE COMPETÊNCIA MIDIÁTICA POR TIPO DE SISTEMA EDUCACIONAL}

Resumo. A educação voltada à alfabetização midiática no Equador ganhou relevância especial na última década. Tanto acadêmicos quanto pesquisadores apontaram que o país também precisa, além de reduzir a brecha digital, capacitar alunos, professores e membros da sociedade em geral no uso e no consumo de mídias tradicionais e digitais. Em estudos anteriores constatou-se que o nível de competência midiática se diferencia por tipo de sistema educacional: privado, co-financiado e público. A pesquisa desenvolvida identifica se a tipologia do sistema educativo (educação regular na área urbana, educação regular na área rural, e educação flexível e à distância) é um fator influente na geração da competência midiática. Através de um questionário e com a análise estatística correspondente, obteve-se que os alunos que frequentavam o sistema regular dentro da cidade demonstraram um nível mais alto na competência midiática em comparação com os outros participantes do estudo. Diferenças foram encontradas entre gênero, idade e nível de competência midiática. As aplicações desses resultados são importantes para melhorar as políticas públicas de educação e de treinamento, e 0 acesso à rede e às novas tecnologias.

Palavras-chave: alfabetização midiática / competência midiática / sistema educacional / Equador 


\section{INTRODUCCIÓN}

La educación en alfabetización mediática y la investigación de sus resultados y logros ha cobrado importancia desde hace algunos años en países en desarrollo como es el caso de Ecuador. En el país, los ciudadanos dedican gran cantidad de horas a estar frente a las pantallas de televisión y de computadoras sin ejercer muchas de las veces un uso apropiado de ellas (Marín Gutiérrez, Rivera Rogel y Celly Alvarado, 2014). Sin embargo, el internet y las redes sociales en la actualidad son alternativas de entretenimiento y de información para los más jóvenes (Suing, Ortiz, Salazar y Vásquez, 2017). Un estudio reciente realizado en el Ecuador señala que la tendencia a perder el control del uso del internet entre estudiantes va en aumento, lo que interfiere con su vida académica y social (García-Umaña y Tirado-Morueta, 2018). Por lo tanto, la necesidad de aplicar medidas educativas para promover el uso responsable de los medios y sobre todo de las nuevas tecnologías es una prioridad. Ahora bien, una solución es el educar en alfabetización mediática y digital a los jóvenes ecuatorianos; para ello, se considera esencial identificar el nivel de alfabetización mediática en una muestra de estudiantes ecuatorianos $y$, además, determinar si el tipo de régimen educativo es un factor que influye en las competencias mediáticas adquiridas.

\section{LA EDUCACIÓN EN ALFABETIZACIÓN MEDIÁTICA EN ECUADOR}

En primer lugar, es importante hacer mención de lo que significa alfabetización mediática y, a su vez, lo que conlleva tener competencia mediática.

La educación en alfabetización mediática es entendida por los académicos e investigadores como la habilidad que tiene una persona para acceder, analizar, evaluar y comprender de forma crítica los mensajes mediáticos y, además, poder comunicar mensajes en una amplia variedad de formas y de plataformas que pueden abarcar desde medios impresos hasta redes sociales (Aufderheide, 1993; Austin, 2014; Koltay, 2011).

Ahora bien, el concepto de competencia mediática involucra el dominio de conocimientos, destrezas y actitudes que se consideran necesarios para relacionarse con los medios y las nuevas tecnologías (J. Ferrés y Piscitelli, 2012), dichas competencias pueden ser enmarcadas en torno a las seis dimensiones que proponen Ferrés y Piscitelli (2012): lenguaje, tecnología, procesos de recepción e interacción, procesos de producción y difusión, ideología y valores, así como la dimensión estética. El presente estudio mide el nivel de competencias mediáticas utilizando la propuesta de los mencionados autores. A continuación, en breves rasgos, se explica de qué trata cada dimensión.

La dimensión ideología y valores explora la capacidad de aprovechamiento de las nuevas herramientas para el compromiso responsable y ciudadano. A su vez determina la habilidad y la actitud ética para buscar información, evaluar la fiabilidad de las fuentes, 
detectar las intenciones o intereses subyacentes en producciones corporativas y en populares, su ideología y valores explícitos. La dimensión y sus indicadores permiten identificar la actitud y capacidad crítica de los estudiantes en relación con los medios y el conocimiento sobre la responsabilidad social.

La dimensión lenguaje se entiende como la capacidad de interpretar, valorar, comprender y analizar los diversos mensajes, y establecer relaciones entre ellos. En esta dimensión se pretende determinar la capacidad de los estudiantes para expresarse mediante una amplia gama de sistemas de representación y de significación. La importancia de elegir y de modificar productos existentes y darles un nuevo sentido y valor.

La dimensión tecnología, dentro del ámbito del análisis, trata la comprensión de las innovaciones tecnológicas, el papel que desempeñan, la habilidad para interactuar con ellas y de desenvolverse en entornos multimodales y multimediales. En cuanto al ámbito de la expresión, se refiere a poder manejar con corrección las herramientas tecnológicas y comunicativas en los nuevos entornos digitales, poder manipular imágenes y sonidos y representar la realidad.

La dimensión de la recepción e interacción determina cómo los estudiantes reciben e interaccionan con los mensajes, si ejercen sus derechos y deberes frente al uso y consumo de los medios. Se analiza la actitud activa en la interacción con las pantallas vista como oportunidad para construir una ciudadanía más plena. Además, se evalúa la capacidad de seleccionar y analizar lo que consume en medios, y cuán capaz es de valorar efectos cognitivos y emocionales.

La dimensión estética determina la sensibilidad frente a los medios y sus productos, al reconocer si una producción mediática se adecúa o no a unas exigencias mínimas de calidad. La capacidad de producir mensajes comprensibles, que incrementen los niveles de creatividad, originalidad y sensibilidad.

Por último, el análisis de la dimensión producción y difusión permite determinar el conocimiento que los estudiantes tienen sobre cómo producir mensajes audiovisuales. Indica la capacidad de seleccionarlos, empoderarse y transformarlos en nuevas producciones con nuevos significados. Para ello es necesario determinar el conocimiento que tienen de los procesos y de la infraestructura involucrada en la producción

Varios estudios han señalado que el nivel de competencias mediáticas de los estudiantes de educación general básica en el sur de Ecuador es medio (Rivera, Ugalde, González y Salinas, 2016; Ugalde y González-Cabrera, 2016). Este resultado no se puede considerar del todo negativo si se toma en cuenta que en el año 2012, el 21,4 \% de la población ecuatoriana era analfabeta digital, es decir, no tenía teléfono celular activado, ni había usado computadora ni internet en dicho año (Instituto Nacional de Estadística y Censos, 2017). 
Por otro lado, un estudio empírico realizado en el país ha mostrado que el acceso al internet está asociado a mayores habilidades operativas necesarias para su uso y que el nivel de educación de los padres influye en el acceso de los hijos al internet, mucho más que el ingreso familiar (Tirado, Mendoza, Aguaded y Marín, 2017). Sin embargo, el Ecuador como muchos países latinoamericanos presenta una brecha digital en el uso y acceso a las TIC entre hijos y padres, así como entre profesores y estudiantes. Cabe recalcar que uno de los factores significativos para esta brecha es el nivel socioeconómico de las familias (Chamorro, 2018; Mintel y Senescyt, 2019).

Los hallazgos de un estudio reciente señalan que entre los estudiantes y docentes universitarios en el Ecuador existe una brecha digital en cuanto al uso y manejo de las tecnologías de la información y comunicación en el proceso de enseñanza aprendizaje (Paredes, 2019). Asimismo, una investigación comparativa entre Ecuador y Colombia encontró un nivel bajo en alfabetización mediática en los profesores participantes (Rivera-Rogel, Zuluaga-Arias, Ramírez, Romero-Rodríguez y Aguaded, 2017). Estas falencias por parte de los docentes han generado preocupación en el ámbito educativo, por tanto, mejorar el nivel en competencia mediática y digital en la formación docente es una de las prioridades para lograr una adecuada inserción de las tecnologías en todos los procesos educativos (Quiroz, Miranda, Gisbert, Morales y Onetto, 2016).

Por último, una revisión de varios estudios sobre el estado actual de la educación en alfabetización mediática en Ecuador señala que se tiene que dar una mayor importancia al componente pedagógico que al tecnológico, ya que se han demostrado falencias y vacíos tanto en los profesores como en los estudiantes en todos los niveles, a pesar de contar con acceso a la tecnología (Rivera, Mendoza-Zambrano, Gutiérrez y Benavides, 2018).

\section{LA SITUACIÓN SOCIOECONÓMICA Y SU IMPACTO EN LA EDUCACIÓN EN ALFABETIZACIÓN MEDIÁTICA}

La educación y el acceso universal a las tecnologías de información y comunicación en especial para las personas y colectividades que carezcan de dicho acceso o lo tengan de forma limitada son derechos establecidos en la Constitución de la República del Ecuador (2008), sin embargo tanto en Ecuador como en otros países latinoamericanos "los pobres reciben una educación de menos calidad, cuentan con maestros menos preparados y sufren cierta discriminación en los insumos necesarios" (Basdresch, 2001, p. 77).

Aunque la brecha digital en el acceso físico a internet en los países en desarrollo se está cerrando con respecto a países desarrollados, como es el caso de Ecuador, que está entre los países sudamericanos con mayor acceso a internet (World Economic Forum, 2019), se está abriendo una nueva brecha en su uso social. Los resultados del estudio realizado por Tirado-Morueta, Mendoza, Marín y Mendoza (2017) muestran que la influencia de los factores sociodemográficos es mayor con respecto al acceso físico 
a Internet y esta influencia disminuye con respecto a niveles más complejos de uso de Internet. En otras palabras, los datos muestran que un alto estatus sociofamiliar no garantiza el acceso a niveles de uso de internet más complejos; sin embargo, un estado bajo sí es un factor de riesgo.

\section{METODOLOGÍA}

El tipo de investigación fue no experimental, transversal, cuantitativa, descriptiva y correlacional. El estudio se desarrolló en el cantón Cuenca, provincia del Azuay, al sur del Ecuador. Se contó con estudiantes de instituto del sistema educativo regular zona urbana ( $N=707)$, estudiantes de la zona rural $(\mathrm{N}=372)$ y del sistema flexible y a distancia ( $\mathrm{N}=296)$. En la mayoría de los establecimientos se pudo aplicar el cuestionario en formato online, mientras que en algunos colegios de la zona rural se aplicó el mismo cuestionario en formato impreso. El cuestionario fue realizado originalmente por un grupo de investigación en España [para más información, ver: goo.gl/oQ5MVX], validado previamente en Ferrés et al. (2011) y adaptado al contexto ecuatoriano.

Del total de los participantes $(\mathrm{N}=1375)$ del estudio, 748 fueron de género femenino $(54,4 \%)$ y 627 de género masculino (45,6\%). Los estudiantes de la zona rural tenían una media de edad de 15,4 años, los del sistema de educación flexible y a distancia una media de 21,6 años y los de sistema regular zona urbana tenían una media de 15,5 años.

Para identificar el nivel de alfabetización mediática a través de las seis dimensiones de Ferrés y Piscitelli (2012): lenguaje, tecnología, procesos de interacción, procesos de producción y difusión, ideología y valores, y dimensión estética, se procedió a crear un índice por cada tipo de dimensión y por cada tipo de sistema educativo. Para el procesamiento de datos y análisis de los resultados se manejó el software estadístico SPSS. Para cumplir los objetivos de investigación se realizó la prueba estadística t de Student, que ayuda a determinar la diferencia de medias o promedios de los grupos de estudio.

\section{RESULTADOS}

En primer lugar, fue necesario determinar si los estudiantes participantes del estudio habían recibido formación en comunicación audiovisual y digital. De los 1375 estudiantes, 208 (15,1 \%) reportaron que no habían recibido formación en comunicación audiovisual y digital, 931 (67,7 \%) señalaron que recibieron alguna formación y 236 (17,1 \%) expresaron que habían tenido bastante formación. Los participantes del régimen a distancia y flexible fueron los que más indicaron que habían recibido formación en comunicación audiovisual y digital frente a los otros estudiantes, su promedio fue superior y estadísticamente significativo sobre el promedio general de 2 puntos (alguna formación) ( $t=(295)$ 2.618, $p=.009$ ). 
Ahora bien, para identificar el nivel de competencias mediáticas en las seis dimensiones, se procedió a obtener el promedio obtenido por grupo, y para determinar si la tipología del sistema educativo (educación regular zona urbana, educación regular zona rural y educación flexible y a distancia) es un factor influyente en el nivel de competencias, se comparó el promedio obtenido por cada grupo de estudio, tal como se explica a continuación.

Mediante la prueba t de Student, que compara los promedios obtenidos (sobre 2 puntos) en cada dimensión por los tres grupos de estudio, se obtuvo que en la dimensión tecnología los estudiantes del sistema regular zona urbana obtuvieron el promedio más alto $(M=1.20, D T=.28)$, seguidos por los estudiantes de la zona rural $(M=1.12, D T=.28)$ y luego por los estudiantes del sistema a distancia y flexible $(M=.89, D T=.26)$. La diferencia de muestras emparejadas fue estadísticamente significativa (véase tabla 1).

Tabla 1

Diferencia de medias: dimensión tecnología

\begin{tabular}{lccccc}
\hline Tipo de sistema educativo & $M$ & $D T$ & $t$ & $g l$ & $p$ \\
\hline Regular-urbana vs. rural & .08 & .41 & 3.754 & 371 & .000 \\
Regular-urbana vs. distancia/flexible & .29 & .38 & 13.279 & 295 & .000 \\
Rural vs. distancia/flexible & .25 & .39 & 11.287 & 295 & .000 \\
\hline
\end{tabular}

Nota: Los grados de libertad ( $\mathrm{gl}$ ) se ajustan a la muestra menor.

En la dimensión lenguaje, los estudiantes del sistema regular zona urbana obtuvieron el promedio más alto $(M=1.27, D T=.37)$, frente al promedio obtenido por los estudiantes de la zona rural $(M=1.11, D T=.38)$ y por los del sistema a distancia y flexible $(M=.91, D T=.32)$. La diferencia de muestras emparejadas fue estadísticamente significativa (véase tabla 2).

Tabla 2

Diferencia de medias: dimensión lenguaje

\begin{tabular}{lccccc}
\hline Tipo de sistema educativo & $M$ & $D T$ & $t$ & $g l$ & $p$ \\
\hline Regular-urbana vs. rural & .16 & .54 & 5.774 & 371 & .000 \\
Regular-urbana vs. distancia/flexible & .33 & .49 & 11.812 & 295 & .000 \\
Rural vs. distancia/flexible & .22 & .49 & 7.861 & 295 & .000 \\
\hline
\end{tabular}

Nota: Los grados de libertad ( $\mathrm{gl}$ ) se ajustan a la muestra menor. 
En la dimensión procesos de recepción e interacción fueron los estudiantes del sistema regular zona rural los que consiguieron un promedio marginalmente más alto $(M=.90, D T=.28)$ en comparación con los estudiantes de la zona urbana $(M=.88, D T=.28)$ y con los del sistema a distancia y flexible $(M=.80, D T=.28)$. Sin embargo, en este caso, la diferencia de muestras emparejadas fue estadísticamente significativa solamente al comparar a los estudiantes de la zona rural y de la zona urbana con los de distancia/ flexible, ya que la diferencia entre los de sistema regular urbana vs. rural no resultó estadísticamente significativa (véase tabla 3 ).

Tabla 3

Diferencia de medias: procesos de recepción e interacción

\begin{tabular}{lccccc}
\hline Tipo de sistema educativo & $M$ & $D T$ & $t$ & $g l$ & $p$ \\
\hline Regular-urbana vs. rural & -.02 & .40 & -.968 & 368 & .334 \\
Regular-urbana vs. distancia/flexible & .06 & .38 & 2.911 & 295 & .004 \\
Rural vs. distancia/flexible & .10 & .39 & 74.325 & 292 & .000 \\
\hline
\end{tabular}

Nota: Los grados de libertad ( $\mathrm{gl}$ ) se ajustan a la muestra menor.

En cuanto a la dimensión procesos de producción y difusión, se encontró que los estudiantes del sistema regular zona urbana alcanzaron el promedio más alto $(M=.65$, $D T=.49)$, frente a los de la zona rural $(M=.49, D T=.45)$ y a los del sistema a distancia y flexible $(M=.19, D T=.26)$. Sin embargo, como se puede apreciar, en esta dimensión los promedios son más bajos que en las otras. La diferencia de muestras emparejadas fue estadísticamente significativa (véase tabla 4).

Tabla 4

Diferencia de medias: procesos de producción y difusión

\begin{tabular}{lccccc}
\hline Tipo de sistema educativo & $M$ & $D T$ & $t$ & $g l$ & $p$ \\
\hline Regular-urbana vs. rural & .16 & .66 & 4.652 & 371 & .000 \\
Regular-urbana vs. distancia/flexible & .45 & .56 & 13.701 & 295 & .004 \\
Rural vs. distancia/flexible & .33 & .53 & 10.790 & 295 & .000 \\
\hline
\end{tabular}

Nota: Los grados de libertad ( $\mathrm{gl}$ ) se ajustan a la muestra menor. 
Ahora bien, en la dimensión ideología y valores se halló que los estudiantes del sistema regular zona rural lograron el promedio más alto $(M=.94, D T=.27)$, en comparación con los de la zona urbana $(M=.88, D T=.25)$ y los del sistema a distancia y flexible $(M=.78, D T=.25)$. La diferencia de muestras emparejadas fue estadísticamente significativa (véase tabla 5).

Tabla 5

Diferencia de medias: ideología y valores

\begin{tabular}{lccccc}
\hline Tipo de sistema educativo & $M$ & $D T$ & $t$ & $g l$ & $p$ \\
\hline Regular-urbana vs. rural & -.06 & .37 & -3.109 & 364 & .002 \\
Regular-urbana vs. distancia/flexible & .08 & .35 & 4.018 & 293 & .000 \\
Rural vs. distancia/flexible & .15 & .37 & 6.959 & 288 & .000 \\
\hline
\end{tabular}

Nota: Los grados de libertad (gl) se ajustan a la muestra menor.

Por último, en la dimensión estética los estudiantes del sistema regular zona urbana alcanzaron la media más alta $(M=1.35, D T=.27)$, seguidos por la zona rural $(M=1.30, D T=$ .28) y por los del sistema a distancia y flexible $(M=1.27, D T=.34)$. La diferencia de muestras emparejadas fue estadísticamente significativa (véase tabla 6).

Por otra parte, se comprobó si la edad era un factor influyente en el nivel de competencia mediática. Cabe señalar que los estudiantes del sistema educativo a distancia y flexible son jóvenes mayores que interrumpieron sus estudios regulares por diversas razones, o trabajan y estudian a la vez.

Tabla 6

Diferencia de medias: estética

\begin{tabular}{lccccc}
\hline Tipo de sistema educativo & $M$ & $D T$ & $t$ & $g l$ & $p$ \\
\hline Regular-urbana vs. rural & .04 & .39 & 2.355 & 370 & .019 \\
Regular-urbana vs. distancia/flexible & .08 & .43 & 3.454 & 294 & .001 \\
Rural vs. distancia/flexible & .05 & .41 & 2.234 & 294 & .026 \\
\hline
\end{tabular}

Nota: Los grados de libertad ( $\mathrm{gl}$ ) se ajustan a la muestra menor. 
Con las pruebas post-hoc de Tukey y Dunnett para comparación múltiple, se obtuvo que en la dimensión tecnología los estudiantes de 17 años obtuvieron un promedio más alto que los estudiantes menores de 14 años (diferencia de medias: .09, $p=.018$ ) IC $95 \%$ $[L I=.00 ; L S=.19]$. Asimismo ocurrió en la dimensión lenguaje (diferencia de medias: .14, $p=.018)$ IC 95 \% [LI=.02; $L S=.27$; mientras que en la dimensión procesos de producción y difusión los participantes de 16 y 17 años obtuvieron un promedio mayor que los de 14 años (diferencia de medias 16 vs. 14: .23, $p=.000$ ) IC $95 \%$ [ $L I=.09$; $L S=.38$ ]; (diferencia de medias 17 vs. 14: .17, $p=.025$ ) IC $95 \%$ [ $L I=.01 ; L S=.33]$. Por último, en la dimensión estética se obtuvo una diferencia en el promedio entre los estudiantes de 17 años frente a los de 14 años (diferencia de medias: .10, $p=.021$ ) IC $95 \%$ [LI=.01; $L S=.20]$.

Por otro lado, mediante la prueba t de Student de muestras independientes se obtuvo una diferencia estadísticamente significativa en los promedios obtenidos por género en las dimensiones: tecnología, procesos de recepción e interacción y dimensión estética. Las participantes de género femenino obtuvieron una media más alta en la dimensión estética $(M=1.36, D T=.27)$ que los estudiantes de género masculino $(M=1.31, D T=.29)$ [t $(705)-2.115, p=.035]$. Mientras que los estudiantes de género masculino obtuvieron un promedio más alto en la dimensión tecnología $(M=1.20, D T=.29)$ en comparación con las participantes de género femenino $(M=1.14, D T=.28)$ [ $t(705) 2.710, p=.007$ ]. Asimismo, los estudiantes de género masculino alcanzaron una media más alta $(M=.89, D T=.28)$ que las mujeres $(M=.81, D T=.25)$ en la dimensión procesos de recepción e interacción; la diferencia fue estadísticamente significativa [t (705) 4.163, $p=.000]$.

\section{DISCUSIÓN}

Los resultados demostraron que tanto la tipología del sistema educativo (educación regular zona urbana, rural y educación flexible y a distancia) como la edad y el género son factores que pueden influir en el nivel de competencias mediáticas. Sin embargo, los resultados pueden variar en diferentes contextos, así como con otros niveles educativos, tanto superiores como de básica.

Fueron los participantes del régimen a distancia y flexible los que indicaron que habían recibido mayor formación en comunicación audiovisual y digital ( $t=(295) 2.618$, $p=.009$ ) sobre el promedio general de 2 puntos (alguna formación), en comparación con lo que expresaron los otros participantes. Sin embargo, los resultados demuestran que los estudiantes de este sistema educativo obtuvieron los promedios más bajos en todas las dimensiones. Por tanto, se comprueba la desigualdad existente entre los estudiantes de los sistemas educativos regulares (urbano y rural) frente a los del sistema a distancia/flexible. Ahora bien, este resultado encuentra explicación en el hecho de que los estudiantes del sistema a distancia y flexible entran dentro del grupo "en situación de 
vulnerabilidad y exclusión, son jóvenes y adultos de 15 años en adelante que por diversas causas no han podido concluir sus estudios en la educación escolarizada obligatoria en la edad correspondiente" (Morán y Morán, 2017, p. 29), lo que justifica en parte el resultado encontrado en el presente estudio. Más aún, si tomamos en cuenta que para la mayoría de estos estudiantes de sistema flexible y a distancia, la educación no es su actividad principal, muchos de ellos trabajan y tienen otras obligaciones económicas que limitan la cantidad y calidad de tiempo dedicado al estudio, situación que se evidencia también en otros países como Argentina (Miranda, 2008). Además, Torres e Infante (2011), en un estudio realizado en Ecuador para identificar la desigualdad digital en la universidad, concluyeron que el nivel de ingreso incidía en las posibilidades de acceso y de uso de las herramientas y de los recursos de internet.

Solamente en los participantes de 17 años se obtuvo una diferencia en el nivel de competencia mediática frente a los menores (14 años). Se encontró que los estudiantes de género masculino demostraron un mayor nivel de competencia en las dimensiones tecnología y procesos de recepción e interacción frente a sus compañeras mujeres, mientras que ellas demostraron un nivel más alto en la dimensión de estética. Estos resultados encuentran sustento en lo detectado por Gil-Juárez et al. (2011), quienes, al realizar una revisión sistemática de los hallazgos de diversas investigaciones, concluyen que las mujeres son minoría en las diferentes carreras universitarias y profesiones vinculadas a las TIC. Algunas de las causas de este fenómeno pueden pensarse como "barreras de acceso", como pueden ser la falta de modelos femeninos vinculados a la tecnología, los estereotipos masculinos y generalmente negativos asociados a la informática (imagen de nerd), las dificultades y la hostilidad del ambiente académico y laboral en el campo tecnológico para las mujeres.

Con el fin de combatir la desigualdad, España ha generado programas con recursos en plataformas online para el uso de las TIC por parte de las mujeres [véase más en: https://bit.ly/2q3SZAP] con el objetivo de disminuir la brecha digital de género, presente en el acceso a la tecnología, en la utilización que se hace de ella y al uso de los servicios TIC más avanzados (Fundación Directa, 2011).

En el Ecuador existe una diferencia en el uso de computadoras, así como en el acceso al internet entre hombres y mujeres; aunque la tenencia de teléfono celular activado ha crecido entre las mujeres, son los hombres quienes mantienen el porcentaje más alto de tenencia de teléfonos inteligentes. Por último, el porcentaje de analfabetismo digital en las mujeres es mucho más alto que el de ellos (Ecuador en cifras, 2017). Por lo tanto, es importante recalcar en este punto que la mayor presencia de recursos en internet con capacidad de empoderar a las mujeres las ayuda y facilita para la adquisición de competencias mediáticas, formación en TIC, empleo y, en general, para contar con recursos que multipliquen exponencialmente sus posibilidades de logro personal. 
El desarrollo de este tipo de recursos permitirá que las brechas digitales por género vayan disminuyendo.

Si se consideran los resultados obtenidos por dimensiones en el presente estudio, la dimensión producción y difusión es la peor evaluada (el promedio más alto fue de .65 sobre dos puntos), lo que se puede deber al nivel superior de dificultad de las preguntas de esta categoría que exigían la demostración de conocimientos. Los resultados negativos reflejan el bajo conocimiento de los estudiantes sobre la producción audiovisual e indican la poca capacidad para seleccionar, empoderar y transformar los conocimientos en nuevas producciones con nuevos significados. Es decir, los estudiantes se limitan a un papel receptor de contenido. Estos resultados muestran la misma tendencia que los obtenidos en España (Ferrés, Aguaded-Gómez y García-Matilla, 2012).

La dimensión mejor evaluada en los tres grupos investigados es la estética, hecho que quizás obedece a que esta dimensión se mide con menos preguntas que las demás (tres), de las cuales solo una pregunta, la peor evaluada, no es autoperceptiva (Ugalde y González-Cabrera, 2016), lo que a la postre pone de manifiesto que, a pesar de ser la dimensión mejor evaluada, los resultados aún son precarios y representan un reto respecto al cultivo de la sensibilidad artística y estética (Ferrés et al., 2013). Además, en esta pregunta obtienen mejores resultados las estudiantes mujeres, mientras los estudiantes varones lo hacen en dimensiones como producción y difusión, lo que coincide con resultados obtenidos no solamente en otros países latinoamericanos, sino también en España (Masanet, Contreras Pulido y Ferrés, 2013).

En síntesis, los estudiantes de la zona urbana tienen mejor competencia mediática que los del área rural y de régimen flexible y a distancia, ya que obtienen los mejores resultados en cuatro de las seis dimensiones evaluadas (tecnología, lenguaje, producción y difusión, y estética); mientras que los estudiantes del sector rural presentaron un promedio más alto en las dimensiones de procesos de recepción e interacción, y de ideología y valores. Este último resultado puede obedecer al mismo entorno en el que se desarrollan estos estudiantes, en el que existe menor influencia externa y mayor apego a tradiciones locales muy ancladas a valores ancestrales e ideales, como el Sumak Kawsay, en que el buen vivir se refleja en mayor respeto por la naturaleza, la organización comunitaria (Macas, 2010), entre otros aspectos que refuerzan la ideología y los valores.

\section{REFERENCIAS}

Aufderheide, P. (1993). Media Literacy. A report of the National Leadership Conference on Media Literacy. Recuperado de https://eric.ed.gov/?id=ED365294

Austin, E. W. (2014). Media literacy. En T. L. Thompson (Ed.), Encyclopedia of health communication (Vol. 1-3, pp. 831-833). Thousand Oaks, CA: SAGE Publications Ltd. 
Basdresch, M. (2001). Educación y pobreza: una relación conflictiva. México D.F.: Clacso, Consejo Latinoamericano de Ciencias Sociales.

Chamorro, M. del C. (2018). Brecha digital, factores que inciden en su aparición: Acceso a internet en Paraguay. Población y Desarrollo, (47), 58-67. Recuperado de https:// dialnet.unirioja.es/servlet/articulo?codigo $=6797272$

Constitución de la República del Ecuador. (2008). Asamblea Nacional de la República del Ecuador., Pub. L. No. Publicada en el Registro Oficial No. 449 (2008).

Ecuador en cifras. (2017). Tecnologías de la Información y Comunicación. ENEMDU-TIC 2017. Recuperado 13 de noviembre del 2018, de ecuadorencifras.gob.ec website: http://www.ecuadorencifras.gob.ec/documentos/web-inec/Estadísticas_ sociales/TIC/2017/Ticsporcentaje202017_270718.pdf

Ferrés, J., García, A., Aguaded, I., Fernández, J., Figueras, M. y Blanes, M. (2011) Competencia Mediática. Investigación sobre el grado de competencia de la ciudadanía en España. Gobierno de España, Ministerio de Educación. Instituto de Tecnologías Educativas, Consell de l'Audiovisual de Catalunya.

Ferrés, J., Aguaded-Gómez, I. y García-Matilla, A. (2012). La competencia mediática de la ciudadanía española: dificultades y retos. ICONO14. Revista Científica de Comunicación y Tecnologías Emergentes, 10(3), 23-42. https://doi.org/10.7195/ ri14.v10i3.201

Ferrés, J., García Mantilla, A., Aguaded, I., Fernández, J., Figueras, M., Blanes, M., Álvares Pousa, L., et al. (2013). Competencia mediática. Investigacion sobre el grado de competencia de la ciudadanía en España. Evaluación de la competencia mediática: Los cuestionarios. Creando redes, estableciendo sinergias: la contribución de la investigación a la educación, I seminario internacional REUNI + D. 1-7.

Ferrés, J. y Piscitelli, A. (2012). La competencia mediática: propuesta articulada de dimensiones e indicadores. Comunicar: Revista Científica de Comunicación y Educación, 19(38), 75-82. https://doi.org/10.3916/C38-2012-02-08

Fundación Directa. (2011). Uso de las TIC para la igualdad (p. 128). Recuperado de Fundación Directa website: https://bit.ly/2q3SZAP

García-Umaña, A. y Tirado-Morueta, R. (2018). Digital Media Behavior of School Students: Abusive Use of the Internet. Journal of New Approaches in Educational Research, 7(2), 140-147. https://doi.org/10.7821/naer.2018.7.284

Gil-Juárez, A., Vitores, A. y Vall-llovera, M. (2011). Brecha digital de género: Una revisión y una propuesta. TESI, 12(2), 25-53. Recuperado de https://gredos.usal.es/jspui/ bitstream/10366/100621/1/Brecha_digital_de_genero_Una_revision_y_.pdf 
Instituto Nacional de Estadística y Censos. (2017). El analfabetismo digital en Ecuador se reduce en 10 puntos desde el 2012. Recuperado 26 de marzo de 2019, de Instituto Nacional de Estadística y Censos website: http://www.ecuadorencifras.gob.ec/ el-analfabetismo-digital-en-ecuador-se-reduce-en-10-puntos-desde-el-2012/

Koltay, T. (2011). The media and the literacies: media literacy, information literacy, digital literacy. Media, Culture \& Society, 33(2), 211-221. https://doi. org/10.1177/0163443710393382

Macas, L. (2010). Sumak Kawsay: La vida en plenitud. América Latina en Movimiento, 452 14-16.

Marín Gutiérrez, I., Rivera Rogel, D., \& Celly Alvarado, S. (2014). Estudio sobre formación en competencia audiovisual de profesores y estudiantes en el sur de Ecuador. Cuadernos.info, (35), 119-131. https://doi.org/10.7764/cdi.35.628

Masanet, M. J., Contreras Pulido, P., \& Ferrés, J. (2013). Highly qualified students? Research into the media competence level of Spanish youth. Recuperado de http://rabida. uhu.es/dspace/handle/10272/7950

Mintel y Senescyt. (2019). Libro Blanco. Líneas de investigación, desarrollo e innovación y transferencia del conocimiento en TIC. Recuperado de Ministerio de Telecomunicaciones y de la Sociedad de la Información. Secretaría de Educación Superior, Ciencia, Tecnología e Innovación del Ecuador website: https://www. telecomunicaciones.gob.ec/wp-content/uploads/2019/01/libro-blanco-lineasde-investigacion.pdf

Miranda, A. (2008). Los jóvenes, la educación secundaria y el empleo a principios del siglo XXI. Revista de Trabajo, 4(6), 185-198.

Morán, F. E., \& Morán, F. L. (2017). Preferencia uso de TIC del docente de las unidades educativas para personas con escolaridad inconclusa en el Sistema Nacional Educativo Ecuatoriano. Revista Científica Ciencia y Tecnología, 2(14). Recuperado de http://cienciaytecnologia.uteg.edu.ec/revista/index.php/cienciaytecnologia/ article/view/105

Paredes, W. (2019). Brecha en el uso de tecnologías de la información y comunicación (TIC) básicas y modernas entre estudiantes y docentes en universidades ecuatorianas. Revista Educación, 43(1). https://doi.org/10.15517/revedu.v43i1.27423

Quiroz, J. S., Miranda, P., Gisbert, M., Morales, J. y Onetto, A. (2016). Indicadores para evaluar la competencia digital docente en la formación inicial en el contexto Chileno - Uruguayo / Indicators to Assess Digital Competence of Teachers in Initial Training in the Chile - Uruguay Contex. Revista Latinoamericana de Tecnología Educativa - RELATEC, 15(3), 55-67. https://doi.org/10.17398/1695-288X.15.3.55 
Rivera, D., Mendoza-Zambrano, D., Gutiérrez, I. M. y Benavides, A. V. V. (2018). Competencias mediáticas audiovisuales en Ecuador y perspectivas a futuro. Lumina, 12(1), 111-123. Recuperado de https://lumina.ufjf.emnuvens.com.br/ lumina/article/view/809

Rivera, D., Ugalde, C., González, C. y Salinas, G. C. (2016). Uso que profesores y estudiantes ecuatorianos dan a las tecnologías de la información y la comunicación. Revista ESPACIOS, 37(33). Recuperado de http://www.revistaespacios.com/ a16v37n33/16373302.html

Rivera-Rogel, D., Zuluaga-Arias, L. I., Ramírez, N. M. M., Romero-Rodríguez, L. M. y Aguaded, I. (2017). Media Competencies for the Citizenship Training of Teachers from Andean America: Colombia and Ecuador. Paidéia (Ribeirão Preto), 27(66), 80-89. https://doi.org/10.1590/1982-43272766201710

Suing, A., Ortiz, C., Salazar, G. y Vásquez, S. (2017). Consumption of Audiovisual Media Among High School Students of Ecuador. En Á. Rocha, A. M. Correia, H. Adeli, L. P. Reis, \& S. Costanzo (Eds.), Recent Advances in Information Systems and Technologies (pp. 23-29). Springer International Publishing.

Tirado-Morueta, R., Mendoza, D., Aguaded, I. y Marín, I. (2017). Empirical study of a sequence of access to Internet use in Ecuador. Telematics and Informatics, 34(4), 171-183. https://doi.org/10.1016/j.tele.2016.12.012

Tirado-Morueta, R., Mendoza, D., Marín, I. y Mendoza, M. (2017). The Relativity of Sociodemographic Determinism on the Digital Divide in High School Students in Ecuador. International Journal of Communication, 11(0), 24. Recuperado de https:// ijoc.org/index.php/ijoc/article/view/6666

Torres, J. C. e Infante, A. (2011). Desigualdad digital en la universidad: usos de internet en Ecuador. Comunicar, 19(37), 81-88. https://doi.org/10.3916/C37-2011-02-08

Ugalde, C. y González-Cabrera. (2016). Estudio de competencia mediática en los jóvenes de la ciudad de Cuenca. Primeros resultados (1. ${ }^{\text {a }}$ ed.). Cuenca - Ecuador: Universidad del Azuay.

World Economic Forum. (2019). ¿Cuántas personas usuarias de internet hay en América Latina? Recuperado 27 de marzo del 2019, de Foro Económico Mundial website: https://es.weforum.org/agenda/2019/03/ cuantas-personas-usuarias-de-internet-hay-en-america-latina/ 


\section{ReLAÇ̃̃es entre 0 TEATRO do OPRIMIDO E A MÍDIA-EDUCAÇÃO NA ESCOLA}

MONICA FANTIN'

Universidade Federal de Santa Catarina, Brasil / monica.fantin@ufsc.br

BÁRBARA MALCUT ${ }^{2}$

Universidade Federal de Santa Catarina, Brasil / barbaramalcut@gmail.com

Recibido: 30/3/2019 / Aceptado: 25/4/2019

doi: $10.26439 /$ contratexto2019.n032.4613

Resumo. 0 texto discute a relação entre educação, comunicação e arte na construção de competências culturais e midiáticas entre jovens estudantes na escola. No contexto de uma pesquisa mais ampla sobre multiletramentos e competências midiáticas, foi desenvolvida uma pesquisa de mestrado com o objetivo de entender como os estudantes compreendem a cultura do outro e a própria cultura a partir de pesquisas na internet e de produções midiáticas. Por meio da aproximação entre Mídia-Educação e Teatro do Oprimido (TO) foi proposta uma intervenção didática com a metodologia dos Episódios de Aprendizagem Situada (EAS) com jovens estudantes de uma turma do oitavo ano de uma escola pública de Florianópolis/SC. A potência de tal articulação promoveu experiências educativas e culturais que propiciaram outras narrativas sobre o processo de ensinar e aprender e deram visibilidade a outros olhares dos estudantes sobre si próprios, sobre a mídia, sobre o conhecimento e sobre o entorno cultural, além de promover práticas colaborativas e autorais na escola e fora dela.

Palavras-chave: Mídia-educação / Teatro do Oprimido / escola / episódios de aprendizagem situada / jovens

\footnotetext{
1 Doutora em Educação e Comunicação pela Universidade Federal de Santa Catarina, Brasil. https://orcid. org/0000-0001-7627-21

2 Mestra em Educação e Comunicação pela Universidade Federal de Santa Catarina, Brasil. https://orcid. org/0000-0002-7279-8918
} 


\title{
RELACIONES ENTRE EL TEATRO DEL OPRIMIDO Y LA EDUCACIÓN MEDIÁTICA EN LA ESCUELA
}

Resumen. El texto discute la relación entre educación, comunicación y arte en la construcción de competencias culturales y mediáticas en estudiantes en la escuela. En el contexto de una investigación más amplia sobre alfabetizaciones múltiples y competencias mediáticas, se desarrolló una investigación de maestría con el objetivo de entender cómo los estudiantes comprenden la cultura del otro y la propia cultura a partir de investigaciones en internet y de producciones mediáticas. Por medio de la aproximación entre educación mediática y Teatro del Oprimido (TO), se propuso una intervención didáctica con la metodología de episodios de aprendizaje situado (EAS) con jóvenes estudiantes del octavo año de una escuela pública de Florianópolis/SC. La potencia de tal articulación promovió experiencias educativas y culturales que propiciaron otras narrativas sobre el proceso de enseñar y aprender, y dieron visibilidad a nuevas miradas de los estudiantes sobre sí mismos, los medios, el conocimiento y el entorno cultural, además de promover prácticas colaborativas y de autoría en la escuela y fuera de ella.

Palabras clave: educación mediática / Teatro del Oprimido / escuela / episodios de aprendizaje situado / jóvenes

\section{RELATIONSHIPS BETWEEN THE THEATER OF THE OPPRESSED AND MEDIA EDUCATION AT SCHOOL}

\begin{abstract}
The text discusses the relationship between education, communication and art in the formation of cultural and media competencies among school students. In the context of a broader research on multiliteracy and media competencies, a master's research was conducted to understand how students conceive their own culture and the culture of others from Internet search and media productions. Through the approach between media education and the Theater of the Oppressed (TO), a didactic intervention was proposed using the Episodes of Situated Learning (EAS) methodology in eighth-grade young students from a public school in Florianópolis/SC. The power of such articulation promoted educational and cultural experiences that favored other narratives on the process of teaching and learning; revealed other students' views of themselves, the media, the knowledge and the cultural environment; and fostered collaborative and creative practices in and out of school.
\end{abstract}

Keywords: Media education / Theater of the Oppressed / school / episodes of localized learning / youth 


\section{INTRODUÇÃO}

Embora a internet seja uma das grandes ferramentas que impulsionaram a globalização da cultura nos últimos anos, conforme apontam os teóricos dos Estudos Culturais, não se pode negar a existência de elementos locais ou nacionais na rede. Desta maneira, componentes culturais relacionados à tradição, e/ou específicos de um determinado grupo encontram no mundo virtual uma possibilidade de expressão. Entre os discursos corriqueiros sobre a rede digital, a ideia de que com ela é possível "conhecer o mundo todo" é bastante frequente. Neste sentido, pesquisar aspectos de culturas diferentes a partir da internet e do modo como os estudantes percebem as igualdades e diferenças podem contribuir com sua formação cidadã e aumentar a percepção deles sobre o outro e, também, sobre si próprios.

No entanto, tal discurso pode sugerir uma diminuição da experiência gerada pela vivência na dimensão da corporeidade, na medida em que supõem que apenas a busca online por informações é suficiente para tanto. Além disso, nem sempre se consideram as possibilidades de informações errôneas, visões estereotipadas e falta de fontes confiáveis que podem prejudicar o entendimento sobre a outra cultura. Nesse processo há riscos de apropriações diversas, inclusive visões equivocadas sobre as diferentes culturas e características do outro.

Diante de tais questões, este artigo está embasado em uma investigação na perspectiva da Mídia-Educação (ME), uma pesquisa de mestrado que teve como objetivo geral identificar como a pesquisa na internet e a produção audiovisual de jovens estudantes podem contribuir para a compreensão da própria cultura e de outras. Os objetivos específicos se referiam a: refletir sobre como os estudantes fazem pesquisa na internet; analisar como os estudantes produzem e compartilham conteúdos midiáticos; identificar as competências midiáticas e informacionais dos estudantes; e refletir sobre possíveis aproximações entre a metodologia dos Episódios de Aprendizagem Situada (EAS) e o Teatro do Oprimido (TO) na medida em que tais práticas foram desenvolvidas com os sujeitosatores da pesquisa. Neste artigo, abordaremos aspectos gerais da investigação, com recorte sobre as possíveis relações entre ME, TO e EAS nas práticas escolares.

\section{CULTURA, MÍDIA-EDUCAÇÃO E EPISÓDIOS DE APRENDIZAGEM SITUADA}

\section{Noções de cultura}

Diante da multiplicidade de sentidos relacionados ao termo cultura é importante situar alguns entendimentos sobre tal expressão. Para tanto, faremos o recorte de alguns conceitos que fundamentaram a referida pesquisa. 
No sentido epistemológico do vocábulo (Hall, 1997), as expressões cultura e culturas, quando utilizadas isoladamente, referem-se à noção de que, se antes a cultura era compreendida como resultado das práticas sociais, agora ela é vista como uma variável que constitui tais práticas. Ao conceder à cultura um espaço de centralidade nas discussões das ciências humanas e sociais, Hall (1997) não considera outras dimensões superiores a ela, mas de igual valor: "A cultura é [...] uma parte constitutiva do 'político' e do 'econômico', da mesma forma que o 'político' e o 'econômico' são, por sua vez, parte constitutiva da cultura e a ela impõem limites" (Hall, 1997, p. 14). Percebe-se, portanto, uma forte relação entre cultura e poder. Não sendo determinada por outras instâncias, tais como a política, a econômica ou de mercado, ela torna-se valiosa nos processos de negociação que geram regulações. Vale ressaltar que regulação não significa coerção, tampouco deve ser compreendida sob uma perspectiva necessariamente negativa. Entendida como uma relação entre liberdades e restrições, ela atua como um arranjo das práticas sociais. Aliado a tal compreensão vale destacar o entendimento de cultura como teia e produção de significados proposto por Williams (1958).

Neste artigo, a compreensão de Culturas Escolares comporta tanto a "transmissão" de conhecimentos (Arendt, 1997) quanto a produção/experimentação em sala de aula (Bruner, 2001). Assim, este termo ressalta seu caráter duplo: ao mesmo tempo em que considera a necessidade de promoção criativa e de produção identitária no ambiente escolar, defende-se as instituições de ensino enquanto lugares de transmissão e produção de conhecimentos, de normas e de regulações.

Sobre as Culturas Juvenis, a lógica de dualidade também será defendida tanto na consideração deste período da vida (não determinado por uma idade específica nem apenas por condições sociais, mas conforme interpelações culturais), caracterizado pela experimentação e pelas produções culturais juvenis que superam a estrutura social estabelecida e as culturas já existentes (Pais, 2006), quanto pela necessidade de educação para que os jovens se expressem e utilizem seus saberes, conhecimentos e habilidades de maneira crítica, num exercício de construção afirmativa do futuro (Mead, 2006; Livingstone, 2011).

A complexidade que envolve a Cultura Digital, "uma cultura multimídia, que usa códigos, linguagens e estratégias pragmáticas de comunicação diferentes" (Fantin \& Rivoltella, 2012, p. 96), implica compreender esse conceito em movimento no momento atual, permeado por diálogos entre contextos que, por um lado, demandam globalizações, e por outro, também fortalecem identidades locais. Assim, considerando que "[...] as mídias se tornam mais que instrumentos primordiais da relação com o mundo, configurando-se como formas de cultura, sendo por meio delas que se consolidam novas percepções marcadas por interdependências e interconexões de diversas naturezas" (Fantin \& Rivoltella, 2012, p. 96), estas epistemologias são possibilitadas pelas tecnologias midiáticas que caracterizam a Cultura Digital. 
Nesse quadro, ao abordarmos os Elementos Nacionais/Locais, faremos menção às características de determinado país que, ao formarem códigos de significação que elaboram culturas e constituem identidades, tornam possível relacionar tais elementos do local/ global com a Cultura Digital e as Culturas Juvenis em ambiente escolar. Como o contexto contemporâneo amplia as oportunidades de identificação dos indivíduos, é também através das possibilidades epistemológicas que se definem as práticas culturais.

$\mathrm{Na}$ especificidade das juventudes, que se manifesta principalmente através de experimentações criativas (Pais, 2006), é possível identificar a internet como um ambiente potencial para a produção e difusão das culturas juvenis. No entanto, as mídias não são apenas espaços de produção cultural e arena de significados, elas também se caracterizam como espaço de reprodução com interface tecnológica. Nessa tensão, a Cultura Escolar, como um espaço de criação e experimentação, também propicia práticas com as múltiplas linguagens na construção de competências midiáticas que possibilitam diversas manifestações juvenis e experiências de cidadania.

\section{Mídia-Educação}

Como campo epistemológico e metodológico em construção, a Mídia-Educação constituise na reflexão teórica sobre as práticas midiáticas e culturais que também se configuram em fazer educativo, numa perspectiva transformadora de reaproximar cultura, mídia, educação e cidadania. A Mídia-Educação pode ser compreendida como:

[...] campo de conhecimento interdisciplinar na interseção entre as ciências da educação (didática em particular) e as ciências da comunicação (principalmente a sociologia da comunicação e a semiótica), delineando-se também como possível disciplina; e pode ser entendida como prática social em contextos não só extraescolares. Ou seja, podemos entender a Mídia-Educação como duas áreas de saber e de intervenção em diversos contextos: como práxis educativa com um campo metodológico e de intervenção didática; e como instância de reflexão teórica sobre esta práxis (com objetivos, metodologias e avaliação). (Fantin, 2006, p. 36)

Essa natureza múltipla do conceito de Mídia-Educação, construído ao longo dos anos, também revela suas articulações e movimentos nas perspectivas crítico-reflexiva, instrumental-metodológica e expressivo-produtiva, que se expressam nos termos educação sobre/para as mídias, com as mídias e através das mídias (Rivoltella, 2005). E tais perspectivas também se relacionam com os Direitos das Crianças às mídias, discutidos por estudiosos como Buckingham (2007), Rivoltella (2009), Tufte e Christensen (2009): os chamados 3 Pês (provisão, proteção e participação). Ao compreender que crianças e jovens estão sendo inseridos no 'mundo adulto', perpassado cotidianamente pelos meios de comunicação, não é possível pensar apenas em proteger as crianças, mas sobretudo "[...] ter a coragem de prepará-las para lidar com ele [mundo midiático], compreendê-lo e nele tornar-se participantes ativas, por direito próprio" (Buckingham, 
2007, p. 295). A provisão é entendida como aquilo que se oferece às crianças e aos jovens; a proteção revela o sentido de 'defender' crianças e jovens de informações, consumos e práticas midiáticas inapropriadas; e a participação diz respeito à noção de agência de crianças e jovens. Tais direitos, por vezes, são contraditórios, mas é nessa contradição que a mediação educativa atua.

Nesse cenário mídia-educativo em que os contextos metodológico, crítico e produtivo manifestam-se e interagem com os direitos à provisão, à proteção e à participação; é possível pensar a desconstrução de certos usos de tecnologias por parte de crianças e jovens e fomentar uma cultura que entenda o uso crítico dos meios como prática cidadã. Para Rivoltella (2012, p. 26), "é muito difícil em nossa sociedade sermos cidadãos ativos sem nos valermos da Mídia-Educação", e diante do protagonismo com que certas mídias e tecnologias mediam as relações e promovem interações das mais diversas, educar para a cidadania implica, necessariamente, educar para um uso consciente e responsável das mídias. Ainda segundo o autor (Rivoltella, 2005), os objetivos da educação para a cidadania envolvem: a) aquisição de conhecimentos (de mundo e da realidade cultural, social e econômica, das instituições e seu funcionamento e das leis); b) competências sociais (saber atuar como cidadão, saber cooperar e realizar projetos comuns, resolver conflitos, atuar no debate público); c) competências éticas e relacionais (saber ser solidário, estar aberto à diferença e à alteridade); e d) as competências midiáticas.

E como hoje, numa sociedade em redes, muitos desses processos estão atravessados pela mídia e pelas tecnologias digitais, Rivoltella (2005) destaca que a Mídia-Educação pode ser entendida como a própria educação. Ou seja, para ele, numa sociedade da informação e do conhecimento, a Mídia-Educação torna-se a própria educação, e nessa perspectiva, ela seria não apenas um campo de estudo e intervenção, mas também uma postura mídia-educativa incorporada ao patrimônio de cada professor e educador (Fantin \& Rivoltella, 2012).

\section{Episódios de Aprendizagem Situada}

A perspectiva mídia-educativa não comtempla apenas a inserção crítica e criativa de tecnologias em sala de aula em uma abordagem instrumental e utilitarista, mas também defende que as práticas pedagógicas sejam transformadoras e modificadas, com o intuito de aproximar as escolas da sociedade midiática atual. Nesse contexto, Rivoltella (2013) desenvolveu uma metodologia que problematiza os modos de ensinar e aprender no contexto da cultura digital, de modo a contribuir com a inserção tecnológica em sala de aula: a metodologia dos Episódios de Aprendizagem Situada (EAS). Tal metodologia entende a sala de aula como "arena simbólica, produção de conhecimentos, significações, aprendizagens, interações, negociações de conflitos e tensões" (Fantin, 2015, p. 444), que envolve aspectos da experiência cultural de alunos e professores, as relações 
entre aprendizagens formais e informais, e o papel da escola, entendida como um ecossistema pedagógico e comunicativo.

A metodologia EAS se configura como uma proposta de integração dos dispositivos móveis na didática e fundamenta-se em quatro ideias-chave (Rivoltella, 2013), a saber: o ensino como design (dimensões do planejamento organizativo, da estética da forma ou estilo, e dos conteúdos da cultura; múltiplas linguagens e multiliteracies, inspirado no trabalho de Cope \& Kalantzis [2000]); o aprender fazendo (o trabalho com laboratório e os princípios da escola ativa); a flipped teaching (inversão da lógica da didática tradicional de ensino, inspirada em Freinet [2002] e Mazur [2007]); e a interseção entre neurociências e didática (a neurodidática, o paradigma da simplexidade proposto por Berthoz [2012] e o sistema corpo-mente-cérebro que fundamenta a base das aprendizagens).

Organizada a partir de uma estrutura que prevê três momentos em cada aula, a metodologia EAS envolve: 1) momento prévio: um quadro conceitual ou uma situação-estímulo que encaminha uma atividade preparatória aos alunos; 2) momento operativo: uma microatividade de produção em que o aluno deve resolver um problema ou produzir algum conteúdo sobre a situação-estímulo, individualmente, em pares ou pequenos grupos; 3 ) momento reestruturador: um debriefing sobre o que aconteceu nos momentos anteriores, com retorno sobre os processos ativados e conceitos que emergiram, de modo a refletir sobre os aspectos pretendidos. (Rivoltella, 2013, pp. 52-53)

Vale destacar que as etapas dos EAS estão organicamente relacionadas à estrutura da pedagogia das multiliteracies proposta pelo New Londond Group (NLG) (Cope \& Kalantzis, 2000), que pensa as etapas didáticas conforme o design cultural. Nessa perspectiva, o primeiro momento dos EAS relaciona-se ao Designed, entendido como repertório cultural. 0 segundo momento refere-se ao Designing, ou seja, à ação de modificar, adaptar ou construir significados. E o Redesigned, que corresponde à terceira etapa, configura-se em síntese e ressignificação daquilo que foi elaborado. Ao aproximar o ambiente escolar dos meios digitais, a metodologia EAS pensa na construção cultural que emerge da realidade midiatizada. Nessa perspectiva, "a didática é entendida como montagem de objetos culturais, o planejamento como design, e a avaliação, para além da escola de competências, é entendida na perspectiva das tarefas incorporadas, embeddedtaske dos portfólios (Fantin, 2015, p. 457).

Dessa maneira, a cidadania fomentada pela escola, inerente ao pensamento mídiaeducativo, também é promovida e fomentada pela metodologia EAS, que busca nas tecnologias e no microlearning uma possibilidade de ampliar a participação dos estudantes na escola, na cultura e na sociedade. E é interessante destacar que tanto a Mídia-Educação como a metodologia EAS envolvem um ritmo ternário que se traduz nas perspectivas e nos momentos de reflexão crítica, do saber fazer/expressar e do reconstruir/socializar/ 
compartilhar. E foi essa metodologia que inspirou algumas aproximações com o Teatro do Oprimido em nossas intervenções didáticas na pesquisa empírica.

\section{TEATRO DO OPRIMIDO (TO)}

Com o intuito de ampliar a criticidade e a indagação social de seu público, Bertolt Brecht, escritor e diretor teatral alemão, buscava quebrar a identificação sentimental entre espectador e espetáculo, minimizando a relação fantástica criada pelo ambiente cênico, que, segundo ele, levava a uma diminuição de análise do público em relação ao conteúdo das peças. Para o autor, "não mais era permitido ao espectador abandonarse a uma vivência sem qualquer atitude crítica (e sem consequências na prática), por mera empatia para com a personagem dramática" (Brecht, 1967, p. 75). Para isso, Brecht teorizou o Teatro Épico ou Teatro Dialético que, através das inserções de outras artes como dança, pintura e música, rompia com a aparência realista que outros espetáculos proporcionavam. Para o autor, "não se aspirava, em suma, a pôr o público em transe e a dar-lhe a ilusão de estar a assistir a um acontecimento natural, não ensaiado. A propensão do público para se entregar a uma tal ilusão deve ser neutralizada por meios artísticos" (Brecht, 1967, p. 130). Dessa maneira, o próprio ornamento do espetáculo e sua arquitetura deveriam romper o sentimento de devaneio proporcionado por outras produções teatrais. Com base no teatro de Bertolt Brecht e na pedagogia de Paulo Freire, o brasileiro Augusto Boal criou e teorizou o Teatro do Oprimido (TO). A partir de experimentos cênicos desenvolvidos em diversos países, principalmente na época em que esteve exilado, Boal (2005) buscou unir plateia e artistas dentro do que ele chamou de espect-ator. Dessa maneira, a participação do público tornava-se inerente às apresentações e produções do TO.

Para compreender o formato de montagem desta prática, Boal (2005) criou um esquema, chamado Árvore do Teatro do Oprimido, que ilustra de forma metafórica o processo de desenvolvimento das produções.

Na Figura 1 é possível verificar que, assim como uma árvore necessita de nutrientes e de uma terra fértil para se desenvolver, o TO precisa de elementos como sentimento de solidariedade e multiplicação, conhecimentos ou disposição para aprendizagens sobre política, história, filosofia e economia, além de uma postura ética. Dessa maneira, percebe-se o caráter social intrínseco a esta linha cênica.

Em relação à sustentação do TO, é possível relacionar a função das raízes de uma árvore à importância da imagem, do som e da palavra na produção dos espetáculos. A inserção de outras manifestações artísticas evidenciada por Brecht, portanto, deve estar presente. 


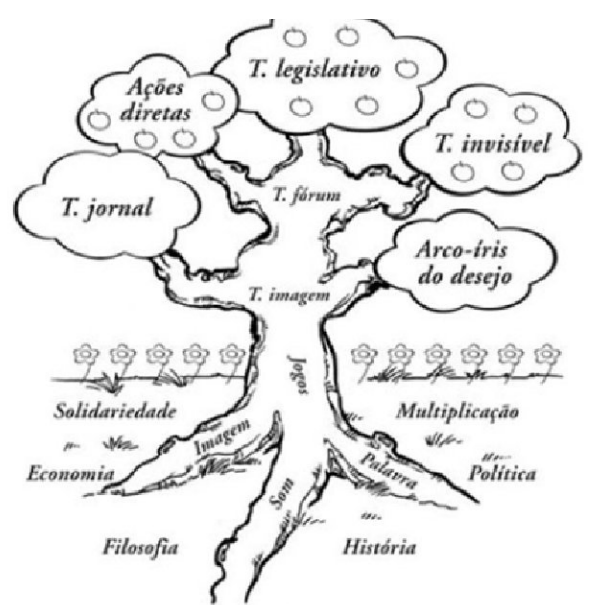

Figura 1. Árvore do Teatro do Oprimido Fonte: Boal (2005)

0 tronco da árvore, ou seja, a estrutura que permite a ela crescer são os jogos livres (caracterizados por práticas corporais que buscam descontruir posturas naturalizadas pelos participantes), assim como as modalidades Teatro Imagem (em que se representa uma cena cotidiana e depois se a remonta, objetivando-se encontrar um conceito de 'ideal', sem utilizar sons ou falas) e Teatro Fórum (atividade com o mesmo princípio da anterior, mas com falas).

Por fim, os galhos, as folhas e a estrutura que possibilitará colher os frutos do TO contam com atividades como o Teatro Jornal (transforma uma notícia em dramatização buscando descontruir seu conteúdo, diagramação, opiniões e outros fatores que possam influenciar o leitor/espectador); as Ações Diretas (teatralização de manifestações massivas - como protestos e torcida organizada - com a qual se busca entender as próprias reações nestes eventos); o Teatro Legislativo (testar possíveis mudanças nas leis a partir das representações de suas consequências); o Teatro Invisível (representação anônima, em local público, sobre um tema polêmico ou de interesse naquele contexto); e o Arco-íris do Desejo (a partir da representação de opressões introjetadas, verifica-se se possuem relação com a vida social).

Através desses jogos teatrais, Boal (2005) objetivava fazer com que os espectadores também se tornassem atores, em um exercício que hoje poderia se assemelhar à noção de prosumers (Toffler, 1980), na medida em que tanto este quanto o espect-ator caracterizam-se como um público não passivo, mas que atua e interfere naquilo que assiste, vivencia ou presencia. Dessa maneira, o teatrólogo brasileiro apresenta uma estrutura composta por quatro etapas para efetivação da formação do espect-ator: Conhecimento do Corpo; Tornar o Corpo Expressivo; Teatro como Linguagem; e Teatro como Discurso.

A primeira etapa, Conhecimento do Corpo, caracteriza-se pelo apontamento de limites e possibilidades físicas dos participantes, através de exercícios e brincadeiras 
teatrais. Para isso, Boal (2005, p. 192) parte do pressuposto de que: "se uma pessoa é capaz de 'desmontar' suas próprias estruturas musculares, será certamente capaz de 'montar' estruturas musculares próprias de outras profissões e de outros status sociais, estará mais capacitada para interpretar outros personagens diferentes de si mesmo".

Verifica-se, assim, que esta etapa inicial também busca fomentar a compreensão do participante sobre o contexto em que o TO está sendo desenvolvido, na medida em que a interação com os outros integrantes the permite um entendimento sobre as posturas enraizadas dos demais.

Considerado um complemento da etapa anterior; o segundo momento, Tornar o Corpo Expressivo, fomenta nos participantes o experimento da interpretação através de alguns jogos, incentivando-os a não só descontruir e reconstruir suas posturas, mas também a práticas sociais por meio da noção de "se colocar no lugar do outro". Desta maneira, não são apenas compreensões físicas que são promovidas, como também compreensões culturais.

A terceira etapa, Teatro como Linguagem, comporta jogos como Teatro Imagem e Teatro Fórum. Aqui, defende-se que "se ao invés de falar, eu tiver que fazer um conjunto de estátuas que signifiquem a 'minha' ideia, neste caso não existirá a dicotomia denotação-conotação. A imagem sintetiza a conotação individual e a denotação coletiva" (Boal, 2005, p. 209). Dessa maneira, não apenas fomenta-se a compreensão cultural dos outros indivíduos e do grupo, mas sobretudo dá-se início a discussões sobre concepções pessoais e coletivas, sempre em busca de ampliar as percepções dos participantes e questionar suas ideias enraizadas.

Por fim, a quarta etapa, o Teatro como Discurso, já considera os integrantes enquanto espectatores, por isso são elaboradas cenas e jogos teatrais com base no interesse de discussão dos participantes. Envolvendo o Teatro Jornal, o Teatro Invisível, o Teatro Legislativo e as Ações Diretas, esta etapa pode também propor novas formas e estratégias de discussão e debate através das artes cênicas, sem limitar-se aos jogos pré-estabelecidos. Assim, efetiva-se a formação do espectador ativo que também opina, discute e interpreta, participando efetivamente do contexto de problematização social promovido pelo Teatro do Oprimido. Esta prática teatral, que também pode ser considerada uma metodologia didática e de pesquisa, foi escolhida para fomentar discussões e análises no desenrolar da etapa empírica da presente investigação.

\section{CENÁRIOS, ATORES E ROTEIROS INVESTIGATIVOS E METODOLÓGICOS}

No contexto da investigação mencionada, ao problematizar a ideia de que com a internet é possível conhecer o mundo todo, pensávamos em desconstruir essa noção do senso comum a partir da questão de pesquisa, qual seja: como os jovens compreendem a cultura 
do outro e a própria cultura a partir de pesquisas na internet e da produção audiovisual no ambiente escolar? (Malcut, 2016). Para tal, orientamo-nos a uma pesquisa empírica que teve como cenário o Colégio de Aplicação (CA) da Universidade Federal de Santa Catarina (UFSC), escolhido tanto pela característica geográfica (era necessário que a escola fosse em Florianópolis) quanto pelo aceite da coordenação e de alguns professores que já estavam participando de uma pesquisa mais ampla, à qual esta investigação era correlata.

Diante da disponibilidade por parte dos professores em participar da pesquisa e também da familiaridade da pesquisadora com o público jovem, foram escolhidos os anos finais do Ensino Fundamental II, mais especificamente uma turma do $8^{\circ}$ Ano, com jovens estudantes de faixa etária entre 13 e 15 anos, no âmbito da disciplina de Língua Portuguesa, ministrada por uma das professoras que aceitou integrar o projeto. Escolhemos, assim, uma das três turmas de $8^{\circ}$ Ano, tendo como critério a compatibilidade de agenda entre a pesquisadora e as aulas da referida professora.

Devido à proposta da pesquisa (que previa a relação dos jovens estudantes com outra cultura) e à proximidade das autoras com investigadores de outros países (desenvolvida em virtude da participação delas em uma rede internacional de pesquisa) também foi estabelecida uma parceria com uma doutoranda de uma universidade do interior da Espanha. Para essa colaboração foi previsto um contato com uma turma de estudantes espanhóis visando ao desenvolvimento de algumas atividades midiáticas para intercambiar experiências, as quais também fizeram parte da presente investigação. Vale ressaltar que esta pesquisa não é comparativa, por isso o campo de trabalho se limita a Florianópolis e à turma de $8^{\circ}$ Ano do Colégio de Aplicação da UFSC, mas tendo como apoio a participação e colaboração dos estudantes espanhóis com uma atividade desenvolvida no contexto das intervenções didáticas.

No contexto brasileiro, os sujeitos atores da pesquisa foram 23 jovens estudantes entre 13 e 15 anos, de ambos os sexos (9 mulheres e 14 homens), de uma mesma turma de $8^{\circ}$ Ano do CA, todos residentes na cidade de Florianópolis. Nas atividades que envolveram estudantes espanhóis, os 25 alunos participaram da pesquisa, também pertenciam a uma mesma turma escolar, com idades entre 14 e 15 anos.

As atividades desenvolvidas no CA aconteceram durante o primeiro semestre de 2015, tendo acontecido o primeiro momento de apresentação na escola, por decisão combinada com a professora da turma (março); seguido de um período de observação participante e de intervenções didáticas (abril a julho) durante as aulas de Língua Portuguesa. No total foram realizados 14 encontros com a turma, entre abril e julho de 2015.

As intervenções didáticas foram elaboradas a partir da metodologia EAS e previam: encontros iniciais de discussão conceitual, com debates sobre o tema cultura; pesquisas 
na internet sobre uma cidade do interior da Espanha; e produção midiática sintetizando os principais tópicos encontrados sobre esta outra cultura. Vale ressaltar que a turma de estudantes espanhóis também deveria realizar a pesquisa e elaborar um trabalho midiático sobre Florianópolis. Foi prevista ainda uma troca dos materiais produzidos, em um exercício de verificação/compreensão da visão que o outro elabora sobre a nossa cultura com base em pesquisas feitas na internet.

Conforme mencionado na seção acima, a presente investigação fundamenta-se na abordagem da Mídia-Educação, e isso significa que, na etapa empírica, as intervenções foram centradas nos processos educativos e nas práticas culturais, e não nos artefatos midiáticos. Através do entendimento de que o investigador e o educador não se separam nestas práticas, foi elaborado um Planejamento de Atividades baseado na Metodologia EAS, para organizar não apenas os tempos/momentos de intervenção; mas, sobretudo, para enfatizar a participação dos estudantes que são entendidos como autores e construtores de relações, conteúdos, informações e aprendizagens.

As atividades foram embasadas nos conteúdos teóricos descritos acima, considerando principalmente a identificação de culturas locais/regionais no contexto digital e convergente da atualidade; os subsídios escolares que contribuíssem para a construção de identidades e culturas juvenis sintonizadas com as demandas da atualidade; as necessidade de letramento midiático nas escolas, em uma concepção que superasse a visão instrumental das tecnologias, traduzida em pesquisas escolares dos estudantes que contemplassem a Mídia-Educação em sua forma e conteúdo; e a necessidade de promover e refletir sobre as competências midiáticas dos jovens.

Além disso, as intervenções didáticas também comportaram atividades performáticas das artes cênicas, especificamente as relacionadas ao Teatro do Oprimido. Esse estilo teatral, entendido não apenas como prática social mas também como metodologia didática e de pesquisa, ao colaborar com a problematização do cotidiano dos participantes propôs a participação ativa dos integrantes como autores e construtores de conhecimentos.

Neste artigo, o recorte escolhido para a reflexão diz respeito a dois encontros, que contaram com atividades de TO dentro da estrutura dos EAS.

Em o primeiro encontro iniciamos pela apresentação de imagens sobre o tema cultura, considerando seu aspecto de hábitos, práticas, cultivo, características regionais e a relação entre local e global. No momento operatório, seguimos para a prática de TO, com uma atividade de Teatro Imagem sobre o tema 'ser de/morar em Florianópolis', e outra de Teatro Jornal problematizando uma notícia previamente levada pelos estudantes sobre a cultura da cidade. No momento reestruturador, finalizamos o primeiro encontro sistematizando os temas cultura, estereótipo e preconceito. 
No outro encontro, realizamos dois EAS: um para a apresentação dos trabalhos da turma, e o outro para a recepção dos trabalhos da cidade espanhola. Assim, nesse primeiro EAS, iniciamos com uma prática teatral de confiança, na qual os alunos, em pé, deveriam soltar-se de encontro ao chão e serem segurados por outros colegas do grupo (trio ou quarteto). Este exercício relaciona-se com uma postura de confiança em relação aos colegas, que deve ser enfatizada em trabalhos em grupo, como ocorreu na produção dos audiovisuais. No momento operatório, assistimos aos trabalhos produzidos e realizamos um Teatro Imagem no final de cada apresentação, para sintetizar o trabalho de produção e/ou o conteúdo dos audiovisuais. No momento reestruturador, sintetizamos em conjunto a experiência de produzir conteúdos digitais sobre outra cultura com base em informações disponíveis na internet. No segundo EAS, iniciamos o momento prévio com encenações que representavam o que os alunos esperavam dos trabalhos dos alunos da Espanha. No momento operativo fizemos a apreciação dos trabalhos; e no momento reestruturador sintetizamos as impressões sobre os trabalhos produzidos pelos estudantes espanhóis. Ficou evidente a surpresa dos estudantes em relação aos trabalhos apresentados, e neste momento nos foi possível problematizar certos estereótipos manifestados sobre a Europa e os preconceitos que os estudantes possuem sobre a própria cultura. Vale ressaltar que, em ambos episódios, a dimensão da corporeidade assumiu o papel de destaque nas atividades propostas, pois os estudantes viveram a experiência corporalmente.

\section{ALGUMAS RELAÇÕES ENTRE MÍDIA-EDUCAÇÃO, TEATRO DO OPRIMIDO E EPISÓDIOS DE APRENDIZAGEM SITUADA}

\section{Culturas em relação no contexto da Cultura Digital}

Para analisar este aspecto, apresentamos o momento operatório do primeiro encontro (Malcut, 2016) que contou com a prática do Teatro do Oprimido. Após uma apresentação inicial, que abordou o tema cultura (enquanto hábitos, costumes, arte, tradição e cultivo), trabalhamos também com a noção de Identidade Cultural, enfatizando que, antigamente, elementos como bandeira, idioma e hino identificavam a cultura de uma sociedade (Bauman, 2001, Hall, 2003). Em contrapartida, com as tecnologias da atualidade, as identidades dos países são uma soma entre as particularidades de determinado país e os elementos globais que o permeiam (Giddens, 2000, Canclini, 1997). Os estudantes afirmaram perceber a influência de elementos globais, principalmente no consumo de marcas e citaram Nike e Hollister como exemplos de empresas estrangeiras inseridas em seus cotidianos.

Partimos, então, para a prática do Teatro do Oprimido (Boal, 2005). Três alunos se dispuseram a iniciar a atividade. Propusemos a eles que criassem mímicas estáticas e 
silenciosas (Teatro Imagem) sobre a cultura de Florianópolis, e os três rapidamente as iniciaram. 0 primeiro representou um pescador segurando uma vara de pesca; o segundo, um banhista; e o terceiro, a prática de stand up paddle. Perguntamos, então, se os colegas conseguiam identificar quais eram as representações. 0 pescador foi facilmente identificado; o banhista foi confundido com uma tainha, elemento também relevante (segundo os alunos) na cultura de Florianópolis; portanto, aceitamos que aquela imagem poderia representar tanto um banhista quanto uma tainha, uma vez que ambos representavam a cultura florianopolitana. A terceira imagem (stand up) foi facilmente identificada e reconhecida como um elemento cultural da atualidade. Alguns alunos não sabiam pronunciar corretamente o nome desta atividade, e um colega comentou: 'Viu? É a cultura americana aqui em Floripa', fazendo referência à noção de Identidade Cultural.

Perguntamos, então, se todos se sentiam representados enquanto florianopolitanos pelas imagens dos três colegas. Alguns alunos comentaram que, embora não gostassem de praia, não era a opinião individual deles que deveria contar, mas a da cidade de maneira geral: 'Eu não gosto de praia. Nunca vou', disse uma aluna. Outra completou: 'Eu até gosto de praia, mas detesto areia'. Então as questionamos se a praia, por este motivo, não representava Florianópolis, e a primeira aluna nos respondeu: 'Representa, sim. Eu não gosto, mas é da cultura, sim'. A outra colega concordou.

Sobre os pescadores, todos concordaram, com certo alvoroço, que eles representavam Florianópolis, demonstrando que este é um elemento forte da cultura da cidade. Questionamos os alunos se alguém da sala era filho de pescador, mas ninguém era. Então indagamos se, pelo fato de ninguém ser filho de pescador naquela turma, aquele elemento não estaria fora da cultura florianopolitana. Todos discordaram enfatizando que conheciam alguns pescadores e que, embora ali ninguém fosse filho de pescador, este ícone representava a cidade e era importante para a cultura de Florianópolis.

Em seguida, perguntamos à turma se havia mais algum elemento não abordado, se mais alguém gostaria de colaborar com aquelas representações, e um colega enfatizou a violência urbana ('os assaltos', nas palavras dele). Convidado para representar esta situação, ele inicialmente não quis, mas, como dois colegas se prontificaram a participar, ele aceitou. Eles representaram então um assalto violento, com chutes e socos, em que o ladrão saiu gritando 'Vai, Corinthians!'. Os colegas repreenderam o aluno por isso, com caras feias, xingamentos e reclamações. Foi um momento em que o próprio grupo se regulou em relação ao preconceito (Hall, 2003).

Outro colega sugeriu que o trânsito também era uma característica cultural da cidade, embora ninguém gostasse. Enfatizamos que a cultura não é apenas formada por elementos que nos agradam, mas que questões 'ruins e chatas', infelizmente, também representam as identidades culturais. Combinamos, então, interpretar o trânsito. Utilizando cadeiras, eles fizeram uma fila de carros, que não saiu do lugar por 'duas 
horas'. Problematizamos que a ideia de 'não sair do lugar por duas horas' poderia ser exagerada, mas concordamos que na interpretação teatral podemos exagerar em alguns aspectos, para enfatizá-los (Boal, 2005).

Seguimos, então, para a prática de Teatro Jornal. Os três colegas que haviam levado notícias sobre Florianópolis fizeram uma breve explicação do assunto de cada matéria, e escolhemos uma que abordava a greve municipal. Como a notícia era grande e corríamos o risco de os alunos se dispersarem com facilidade, lemos o título e o lead (primeiro parágrafo da notícia, que busca sintetizá-la). Os alunos perceberam que o título, Em Florianópolis, greve dos servidores afeta escolas e postos de saúde, sugeria que todos os profissionais da educação e da saúde haviam aderido à greve. No entanto, lendo o primeiro parágrafo, percebemos que entre $60 \%$ e $85 \%$ dos servidores havia aderido de fato. Os alunos resolveram encenar, portanto, o movimento em que os grevistas negociavam com a Secretaria Municipal de Administração, sem esquecer que nem todos os servidores haviam aderindo à greve.

Neste momento, uma das alunas que representava os apoiadores da greve local começou a falar sobre temas do cenário nacional. Alguns colegas riram, e outros reclamaram que ela não sabia o que estava interpretando. Problematizamos que aquela greve era municipal, e não federal. A aluna se defendeu dizendo que não sabia como era uma manifestação de greve e outra colega foi ajudá-la. Elas passaram a protestar dizendo 'estamos em greve'. 0 colega que encenava o servidor contrário à greve quis impedi-las de chegar até o colega que interpretava a Secretaria Municipal de Administração. Houve a encenação de um confronto violento, e a professora da turma comentou que acharia relevante abordar com eles, em outra oportunidade, as noções que possuem sobre manifestações, democracia e greve. Decidimos não abordar estes temas durante aquela aula, pela mudança de foco e quebra no andamento que a discussão poderia gerar, mas estabelecemos que o tema seria retomado em outro momento.

Vale enfatizar o elemento cultural que emergiu desta interpretação: embora estivéssemos vivendo um momento político de decisões e protestos, verificamos que não existe necessariamente uma noção mais clara e consciente do que é manifestação, democracia ou greve entre os estudantes. 0 Teatro do Oprimido (Boal, 2005), neste caso, mostrou-se como uma estrutura de problematização da notícia, em seu jogo Teatro Jornal, mas também permitiu que emergissem estereótipos e concepções pessoais e do grupo. Dessa forma, pudemos evidenciar a conotação individual e a denotação coletiva (Boal, 2005). Além disso, foi-nos possível problematizar a origem das concepções que emergiram, verificando quais mediações (Martin-Barbero, 2009) levaram à estudante a relacionar uma greve municipal a protestos federais, assim como, a relação que os estudantes estabeleceram entre violência e protestos/manifestações. Pensar em cidadania na perspectiva mídia-educativa (Rivoltella, 2012) requer a habilidade de refletir sobre 
os conteúdos midiáticos, assim como sobre as mediações geradas a partir deles para desconstruir e reconstruir a partir de outras bases.

Com base no encontro descrito acima, foi-nos possível identificar importantes elementos sobre o entendimento das culturas locais/regionais no contexto digital e convergente da atualidade. Desde o início das discussões, quando os alunos citaram as marcas Nike e Hollister como internacionalizações presentes em seus cotidianos, pudemos perceber que a hibridização (Canclini, 1997) circunda os estudantes. Durante a prática teatral, quando eles citaram o stand up paddle como pertencente à cultura florianopolitana, esta hibridização tornou-se ainda mais evidente, na medida em que identificaram um elemento global (Giddens, 2000) como característica regional. Em contrapartida, outro elemento cultural levantado e defendido pelos estudantes foi a presença dos pescadores. Assim, pudemos verificar na prática os processos de negociação entre tradicionalismo e inovação inerentes às culturas locais, sobre os quais nos fala Williams (1958). Também merece destaque a percepção que os estudantes tiveram de que a cultura é elaborada na vivência coletiva e, portanto, questões pessoais (como gosto ou não por praia) foram deixadas de lado, assim como elementos negativos (trânsito e violência urbana) foram assumidos como culturais.

Também nos foi possível observar diversos aspectos da cultura digital (Fantin \& Rivoltella, 2012) na realidade escolar dos estudantes. Para este encontro, solicitamos previamente aos alunos que levassem notícias sobre Florianópolis, para serem discutidas em sala. Dos três estudantes que realizaram a tarefa, dois levaram notícias online, entre os quais um entregou um papel com a cópia do site, e outro mostrou o link copiado no caderno, demonstrando o quanto as mídias estão inseridas nas práticas sociais dos estudantes. Por fim, ainda sobre o tema cultura, mas não em seu sentido global/ local, pudemos verificar seu aspecto epistemológico (Hall, 1997). Durante as práticas teatrais, em dois momentos, os estudantes demonstraram claras construções culturais, permeadas por aspectos econômicos e políticos (relacionar o time Corinthians a bandidos e relacionar protestos/manifestações a atos contra a presidente Dilma). Em contrapartida, os colegas exerceram regulações classificatórias sobre as visões estereotipadas, ao repreenderem e criticarem as duas situações.

\section{Construções identitárias de jovens estudantes: mediações escolares}

Considerando a perspectiva de Bruner (2001) que, no ambiente escolar, defende a prática de narrativas em diversos suportes como exercícios de (re)elaboração identitária e (re) formulação cultural dos estudantes, é possível sustentar que as intervenções didáticas da presente investigação ofereceram subsídios aos estudantes de maneira geral. De qualquer forma, uma das atividades merece destaque, sobretudo pela desconstrução provocada e pelo exercício de empoderamento promovido. Ocorrido na última 
intervenção, a recepção dos trabalhos da cidade do interior da Espanha foi polêmica e gerou muitas discussões entre os estudantes.

Antes de dar início à apresentação das produções, solicitamos aos estudantes que encenassem o que eles esperavam dos trabalhos. Dentre as falas que emergiram, podemos destacar frases como 'eles vão humilhar a gente', 'o trabalho deles deve estar bem massa' e 'eles devem saber mais sobre Florianópolis do que a gente'. Perguntamos a um desses estudantes por que ele pensava assim, e a resposta foi: 'porque eles são da Europa'. Questionamos como eles achavam que eram as escolas na Espanha, e os alunos representaram instituições muito equipadas, com televisões e computadores em sala. Vale destacar a seguinte fala: 'as aulas devem ser mais legais em Huelva', que além de demostrar uma visão estereotipada de inferioridade brasileira, relaciona a quantidade de aparatos tecnológicos (imaginados pelos estudantes) à qualidade das aulas.

Explicamos, então, que a escola participante da pesquisa tinha poucos computadores, alguns dos quais quebrados, e que os seus estudantes não tinham acesso à internet. Alguns estudantes duvidaram, pensaram que estávamos brincando, mas prosseguimos dizendo que os alunos da outra cidade não tiveram como produzir audiovisuais na escola e, portanto, haviam feito em casa apresentações multimídia (em slides) sobre Florianópolis.

Os estudantes protestaram mesmo antes de assistirem aos conteúdos, um misto de surpresa e decepção se evidenciou nas posturas, fisionomias e falas. Seguimos para a exibição das apresentações e o momento mais comentado ocorreu durante a exposição do slide de abertura da primeira apresentação, que trazia uma foto do Rio de Janeiro e não de Florianópolis. Entre alguns comentários do tipo 'isso nem é Florianópolis', 'nada a ver', foi lembrado aos estudantes que talvez eles também tivessem cometido erros sobre a cidade espanhola e que seria melhor não avaliar os trabalhos dos estudantes estrangeiros de maneira tão judiciosa. No momento reestruturador, o grupo elencou cinco aspectos sobre os trabalhos vistos: 'repetitivos', pois não foram divididos por temas, como ocorreu em Florianópolis, pois a divisão temática deixa o trabalho mais interessantes; e também porque identificaram dois trabalhos com o mesmo texto: 'acho que foi da Wikipédia', 'Ctrl C Ctrl V', 'sem fontes', 'fotos e informações que não correspondem' e 'informativo' foram algumas das opiniões externadas. No geral, os trabalhos de Huelva abordaram geografia, esportes e festas típicas de Florianópolis.

É importante destacar as especificidades culturais que emergiram nesta atividade. Em relação aos trabalhos produzidos pelos alunos espanhóis, nenhum deles continha o nome dos estudantes que elaboraram as apresentações. Em contrapartida, em relação aos trabalhos feitos em Florianópolis, foi solicitado pela equipe espanhola que a identificação dos estudantes fosse retirada. No momento de recepção dos trabalhos espanhóis em Florianópolis, vários estudantes repararam na ausência dos nomes e consideraram 
uma falha ou erro por parte dos estudantes europeus, pois estavam acostumados a assinar suas atividades escolares. Percebemos, portanto, que uma atitude considerada de proteção à imagem/autoria dos estudantes (no contexto espanhol) pode ser compreendida como concessão e estímulo à autoria dos estudantes (no contexto brasileiros).

Por fim, ao julgar os trabalhos como pouco aprofundados, os estudantes puderam perceber certas representações de Florianópolis nas imagens disponíveis na internet e como um estrangeiro pode ver a cidade a partir disso, concluindo: uma cidade bonita, mas que foi confundida com o Rio de Janeiro. Eles disseram não se sentir representados nas imagens vistas, sobretudo quando retomamos o conteúdo do primeiro encontro, quando através da prática de TO, eles levantaram questões culturais sobre Florianópolis (pescadores, praias, tainhas, stand up paddle, violência urbana e trânsito).

Essa atividade foi importante para descontruir a ideia, até certo ponto colonialista, de que 'tudo da Europa e/ou de fora é melhor', ou que 'Brasil é inferior em relação aos outros países/culturas/contextos'. Considerando que as Culturas Juvenis (Pais, 2006) são formadas pelas interpelações das mais diversas instâncias, podemos refletir sobre quais culturas ajudam a formar esta visão de inferioridade presente nas narrativas dos estudantes. Da mesma forma que, no primeiro encontro, problematizamos a origem de discursos estereotipados (em relação à greve e à violência urbana), e pensamos em possíveis mediações (Martin-Barbero, 2009) de modo a colaborar com outra construção social (Hall, 1997), de modo a tensionar e/ou superar, sobretudo, entre os jovens (Pais, 2006) uma cultura estereotipada de inferioridade sobre o próprio país. A experiência descrita também nos permitiu problematizar uma visão colonialista, mostrando outros contextos, seus problemas e as possibilidades das juventudes em outros países.

Além disso, alguns equívocos identificados na apresentação dos trabalhos contribuíram para certa autocrítica por parte do grupo. Os estudantes, através de comentários, refletiram sobre seus próprios trabalhos, as autorias, as fontes e a veracidade de informações. Ou seja, um exercício de alteridade que colaborou com o olhar para si próprio, contribuindo com a construção das competências midiáticas, entendidas por Ferrés e Piscitelli (2012, p. 76) como a "[...] combinação de conhecimentos, agilidades e atitudes que se consideram necessárias para um determinado contexto", mas que não estavam necessariamente evidenciadas nos trabalhos dos estudantes. Sobretudo se considerarmos o Letramento Informacional (Organização das Nações Unidas para a Educação, a Ciência e a Cultura [Unesco], 2103), podemos verificar que as habilidades de saber encontrar, recuperar e utilizar informações na internet não foram evidenciadas em alguns trabalhos desenvolvidos por estudantes estrangeiros e serviram como questionamento e autocrítica para os próprios alunos florianopolitanos. 


\section{ALGUMAS CONSIDERAÇÕES}

Ao aproximarmos do Teatro do Oprimido e dos Episódios de Aprendizagem Situada em um contexto de sala de aula, podemos verificar em que medida eles se relacionam com a perspectiva mídia-educativa de ensino e pesquisa e, principalmente, como tais propostas se relacionam entre si. Conforme formos buscando aproximar as duas metodologias na pesquisa empírica, nesse momento destacaremos aspectos da possível utilização de ambas em sala de aula.

A metodologia EAS, fortemente relacionada à inserção significativa de tecnologias móveis em sala de aula, prevê uma mudança na estrutura pedagógica na medida em que transfere para o ambiente escolar não apenas a explanação e explicação de conteúdos mas principalmente o questionamento, o aprofundamento e a experimentação dos temas trabalhados. Nesta pesquisa, as práticas midiáticas, em uma perspectiva midiático-educativa, permearam as três etapas do EAS. No momento prévio, por exemplo, vídeos-estímulo foram utilizados como introdução ou apresentação conceitual sobre o tema da aula; no momento operativo foram propostas atividades de produção midiática, análise de conteúdos ou mesmo debates e discussões sobre temas mídia-educativos; e no momento reestruturador, que envolve síntese e o compartilhamento das aprendizagens, tais exercícios foram pensados/realizados em diversos suportes midiáticos. Desse modo, a relação entre os EAS e Mídia-Educação pode ser efetivada na perspectiva de educar para, sobre, com e através das mídias.

Por sua vez, o TO colaborou especialmente com o incentivo à problematização dos alunos sobre seus cotidianos e suas práticas midiáticas. Dessa maneira, considerando a perspectiva midiático-educativa, os jogos da modalidade cênica do TO colaboraram com a reflexão dos estudantes sobre certos estereótipos presentes na mídia e sobre seus usos midiáticos, bem como com a problematização/desconstrução de ideais naturalizadas que possuem sobre os meios.

A partir das atividades do Teatro do Oprimido, portanto, foi-nos possível estimular o questionamento e incentivar os estudantes a pensarem em novas possibilidades sociais. Desse modo, as Práticas de Teatro Imagem e de Teatro Fórum podem servir, por exemplo, como princípios de discussão sobre questões como cyberbullying ou mesmo para problematizar certas práticas midiática dos estudantes. 0 Teatro Jornal também pode colaborar com tal problematização, a partir da desconstrução de reportagens e noticiários sejam eles impressos ou digitais (como informações de portais ou mesmo boatos em redes sociais). As Ações Diretas, que buscam antecipar reações em situações de multidão, brigas e protestos, podem ser direcionadas ao contexto online destas situações, como os fóruns de discussão em que os participantes exibem comportamento extremistas ou externam reações exageradas a comentários e postagens oriundos de redes sociais. 
Nesse contexto, também é pertinente lançar mão do Teatro do Invisível que pode contribuir com a compreensão de reações sociais e oferecer aos alunos uma possibilidade a mais de debate sobre o cotidiano digital e online. Por fim, o Teatro Legislativo pode colaborar com a ampliação de reflexão ao fazer os estudantes pensarem em leis que estejam em voga no contexto nacional, estadual, municipal e, até mesmo, sobre regras da própria instituição de ensino. Assim, questões referentes a permissões e proibições midiáticas em sala de aula (como certos usos do celular, certas formas de fazer pesquisas escolares na internet e a predominância dos usos de certas fontes em sites como Wikipédia) podem ser debatidas, experimentadas e problematizadas pelos estudantes em um contexto de representação cênica.

Dessa maneira, verificamos que tanto o TO quanto a metodologia EAS concordam entre si e podem colaborar com a proposta mídia-educativa de ensino e pesquisa. É possível ainda pensar na relação entre as duas propostas/metodologias -EAS e TO- em atividades que comportem ambas, as quais, a partir desta pesquisa, podem ser assim sintetizadas:

No momento prévio do EAS, pode-se pensar em jogos do TO para desconstrução e reconstrução corporais (inerentes à etapa Conhecimento do Corpo) e para percepções culturais (inerentes à etapa Tornar o Corpo Expressivo) como possibilidades de exercício. Ao entender que estes jogos oferecem maior compreensão no âmbito individual e no âmbito coletivo, é possível utilizá-los para encaminhar as demais atividades da aula, servindo como estímulo para os momentos posteriores.

0 momento operativo pode ser realizado através de jogos da etapa Teatro como Linguagem (Teatro Imagem e Teatro Fórum) e da etapa Teatro como Discurso (Teatro Jornal, Teatro Invisível, Teatro Legislativo e Ações Diretas), com base nas sugestões anteriormente apresentadas, que comportam produções a partir da relação com mídias impressas, digitais, além de mediações orais.

Visto que todas as práticas de TO são finalizadas com a elaboração de uma cena que resume os temas debatidos e enaltece a solução/sugestão/conclusão do grupo, esta finalização pode relacionar-se ao momento reestruturador, pois ambos buscam sintetizar as atividades desenvolvidas, em um exercício de reflexão sobre o processo e a fixação dos conteúdos elaborados. Dessa maneira, Teatro do Oprimido e Episódios de Aprendizagens Situadas dialogam não apenas em suas possibilidades mídia-educativas, mas também através da possibilidade de ambas as práticas serem realizadas ao mesmo tempo. Assim, é possível pensar uma aplicação de EAS em que todos os momentos são compostos por atividades do TO ou mesmo a inserção desta modalidade cênica em apenas um dos momentos da metodologia EAS.

Por fim, nos diálogos entre Mídia-Educação, Teatro do Oprimido e Episódios de Aprendizagem Situada destacamos a importância da problematização do cotidiano por 
meio de diferentes linguagens e jogos da modalidade cênica que potencializem a reflexão sobre mídias, tecnologias, sala de aula e mediações, sempre enfatizando a noção de agência dos estudantes e espect-atores. Como pistas para continuar e aprofundar a reflexão em torno das competências midiáticas e do potencial dialógico das relações e interlocuções evidenciadas acima, elencamos possíveis aproximações da metodologia do TO, seus três princípios éticos-estéticos (reapropriação dos meios de produção teatral; a quebra da quarta parede, que separa público/atores; e o teatro e a intervenção social e política para a transformação) e suas respectivas técnicas com a estrutura da metodologia EAS, seus fundamentos e propósitos, de modo a construir outros roteiros nos diferentes cenários da educação.

\section{REFERÊNCIAS}

Arendt, H. (1997). Entre o passado e o futuro. São Paulo: Perspectiva.

Bauman, Z. (2001). Modernidade Líquida. Rio de Janeiro: Zahar.

Berthoz, A. (2012). La Semplesssità. Torino: Codice.

Boal, A. (2005). Teatro do Oprimido e outras poéticas políticas. São Paulo: Record.

Brecht, B. (1967). Teatro dialético: ensaios. Rio de Janeiro: Civilização Brasileira.

Bruner, J. (2001). A cultura da educação. Porto Alegre: Artmed.

Buckingham, D. (2007). Crescer na era das mídias eletrônicas. São Paulo: Edições Loyola.

Canclini, N. G. (1997). Culturas hibridas: estratégias para entrar e sair da modernidade. São Paulo: EdUSP.

Cope, B., \& Kalantzis, M. (Eds.) (2000). Multiliteracies: literacy learning and the design of social futures. New York: Routledge.

Fantin, M. (2006). Mídia-Educação: conceitos, experiências diálogos Brasil-Itália. Florianópolis: Cidade Futura.

Fantin, M. (2015). Novos Paradigmas da didática e a proposta metodológica dos Episódios de Aprendizagem Situada, EAS. Educação \& Realidade, v. 40, n. 2, p. 443-464. ISSN 2175-6236. http://dx.doi.org/10.1590/2175-623646056.

Fantin, M., \& Rivoltella, P. C. (Orgs.) (2012). Cultura digital e escola: pesquisa e formação de professores. Campinas: Papirus.

Ferrés, J., \& Piscitelli, A. (2012). La competencia mediática: propuesta articulada de indicadores e dimensiones. Comunicar, 38, XIX, p. 75-82. https://doi.org/10.3916/ C38-2012-02-08.

Freinet, C. (2002). La Scuola del Fare. Bergamo: Junior. 
Giddens, A. (2000). 0 mundo na era da globalização. Lisboa: Presença.

Hall, S. (1997). A centralidade da cultura: notas sobre as revoluções culturais do nosso tempo. Educação e Realidade. v. 22, n. 2, pp. 15-46.

Hall, S. (2003). A identidade cultural na pós-modernidade. Rio de Janeiro: DP\&M.

Malcut, B. (2016). Culturas que emergem na escola: pesquisa na internet, produção audiovisual e competências midiáticas de jovens estudantes. (Dissertação de Mestrado). Universidade Federal de Santa Catarina - UFSC, Florianópolis, Brasil.

Martin-Barbero, J. (2009). Dos meios às mediações: comunicação, cultura e hegemonia (6a ed.). Rio de Janeiro: Editora UFJR.

Mazur, E. (2007). Peer Instruction: getting students to think in class. New York: American Institute of Pyisics.

Mead, M. (2006). Cultura e compromisso. Barcelona: Gedisa.

Organização das Nações Unidas para a Educação, a Ciência e a Cultura - Unesco (2013). Alfabetização midiática e informacional: currículo para a formação de professores. Brasília: Unesco.

Pais, J. M. (2006). Busca de si: expressividades e identidades juvenis. In Almeida, M. I. M. de., \& Eugenio, F. (Orgs). Culturas jovens: novos mapas do afeto. Rio de Janeiro: Jorge Zahar.

Rivoltella, P. C. (2005). Media education: fondamenti didattici e prospettive di ricerca. Brescia, La Scuola.

Rivoltella, P. C. (2009). Mídia-Educação e pesquisa educativa. Perspectiva, v. 27, n. 1 pp. 119-140. DOI: https://doi.org/10.5007/2175-795X.2009v27n1p119

Rivoltella, P. C. (2012). Retrospectivas e tendências da pesquisa em Mídia-Educação no contexto internacional. In Fantin, M., \& Rivoltella, P. C. (Orgs). Cultura digital e escola: pesquisa e formação de professores. Campinas: Papirus.

Rivoltella, P. C. (2013). Fare Didattica con gli EAS. Brescia: La Scuola.

Livingstone, S. (2011). Internet literacy: a negociação dos jovens com as novas oportunidades online. Matrizes, v. 4, n. 2, pp. 11-42.

Toffler, A. (1980). A Terceira Onda. Rio de Janeiro: Record.

Tufte, B., \& Christensen, O. (2009, jan./jun.). Mídia-Educação: entre a teoria e a prática. Perspectiva, v. 27, n. 1, pp. 97-116. DOI: https://doi.org/10.5007/2175-795X. 2009v27n1p97

Williams, R. (1958). A Cultura é de todos. Tradução Maria Elisa Cevasco. Recuperado de https://www.scribd.com/document/68474445/A-Cultura-e-Ordinaria1 